\title{
Effects of octacosanol on HMG-CoA reductase and cyclooxygenase-2 activities in the HT-29 human colorectal cancer cell line
}

\author{
Suphaket Saenthaweesuk ${ }^{\mathrm{a}}$, Atcharaporn Thaeomor $^{\mathrm{b}}$, Pornrut Rabintossaporn ${ }^{\mathrm{a}}$, Jarinyaporn Naowaboot ${ }^{\mathrm{a}}$, \\ Nuntiya Somparn ${ }^{\mathrm{a}, *}$ \\ a Preclinical Science, Faculty of Medicine, Thammasat University 12120 Thailand \\ b School of Preclinic, Institute of Science, Suranaree University of Technology, Nakhon Ratchasima 30000 Thailand \\ *Corresponding author, e-mail: nuntiya_tom@hotmail.com
}

Received 24 Mar 2021

Accepted 22 Jul 2021

\begin{abstract}
Octacosanol (OCT) is a major component of policosanol which has been reported to possess antiinflammatory and lipid-lowering effects. Therefore, it was our interest to evaluate the effects of OCT on HMG-CoA reductase (HMGR) and cyclooxygenase-2 (COX-2) activities in a human colorectal cancer cell line (HT-29). Our results demonstrate that $100 \mu \mathrm{M}$ OCT decreased viability of HT-29 cells as analyzed by sulforhodamine B colorimetric assay with more pronounced effects seen in cells treated with atorvastatin (AST) or celecoxib (CLX), the inhibitors to HMGR and COX-2, respectively. Additionally, the activity of HMGR was found to be inhibited in cells treated with OCT, while COX-2 activity was unaffected; these effects were also more pronounced in AST- and CLX-treated cells. In cells treated with OCT, a significant decrease in HMGR protein expression was observed, but there was no alteration in COX-2 protein expression as determined by Western blot. Taken together, our results show that OCT inhibited HT-29 cell growth and that this effect might be attributed to the reduction of HMGR protein expression and activity.
\end{abstract}

KEYWORDS: octacosanol, HMG-CoA reductase, cyclooxygenase, colorectal cancer

\section{INTRODUCTION}

Octacosanol (OCT) is a straight-chain aliphatic 28carbon primary fatty alcohol, the main component of policosanol [1] found in plants, especially sugar cane and rice. OCT has been reported to possess many physiological functions including lipid-lowering and anti-inflammatory effects [2].

Nuclear factor-kappaB (NF- $\kappa \mathrm{B})$ regulates the expression of inflammatory genes including cyclooxygenase-2 (COX-2). The anti-inflammatory effect of OCT has been suggested to involve downregulation of inflammatory factor expression and blockade of the MAPK/NF- $\mathrm{K} / \mathrm{AP}-1$ signaling pathway [3]. OCT isolated from plants has been shown to inhibit nuclear translocation of NF- $\kappa \mathrm{B}$ as well as its DNA binding activity, resulting in downregulation of gene expression downstream of this signaling [4]. Additionally, policosanol has been reported to significantly inhibit COX-1 activity in a dose-dependent manner as well as reduce COX-2 activity by up to $39 \%$, suggesting some inhibitory action on this target [3].

The lipid-lowering effects of policosanol have been documented in several studies, comprising data from both animal models and human trails [4-7]. Apart from polycosanol, reduction of cholesterol level has been reported in mice by feeding the diet with extracts from Antheraea pernyi plant containing many bioactive substances such as hormone and protein mediating immune function [8]. HMG-CoA reductase (HMGR) plays a role in the cellular synthesis of cholesterol. At the molecular level, policosanol treatment reduces cellular HMGR activity through activation of AMPkinase [9].

The effects of non-steroidal anti-inflammatory drugs (NSAIDs) in prevention of human cancers have been emphasized in several studies. Inhibition of COX enzymes (both COX-1 and COX-2) resulting in the altered metabolism of arachidonic acid is a basic conceivable mechanism for the anti-tumor effects of NSAIDs $[10,11]$. COX-2 is inducible and is frequently overexpressed in a variety of tumors. COX-2 inhibitors such as celecoxib (CLX) have been shown to interfere with tumorigenesis and induce apoptosis in colon cancer; therefore, COX-2 is an interesting target for therapeutic and chemoprotective strategies [12].

Statins, potent cholesterol-lowering drugs, exert their effect via inhibition of HMGR. Statins such as atorvastatin (AST) have been shown to exhibit antitumor effects and attenuate metastasis in several studies including both in vitro and in vivo experiments as well as human studies [13-16]. HMGR involves in the production of cholesterol and non-steroidal isoprenoid derivatives, which are necessary for cell growth and differentiation [17]. In vitro and in vivo studies have demonstrated that simvastatin suppresses cancer cell growth by inducing apoptosis and inhibiting cell cycle progression $[18,19]$.

Since policosanol has been suggested to inhibit COX and HMGR activities and OCT is a major component in policosanol, we were interested in evaluating 
the effects of OCT on COX-2 and HMGR activities and thereby its anti-cancer potential, using the HT-29 colon cancer cell line.

\section{MATERIALS AND METHODS}

\section{Chemicals}

OCT (1-Octacosanol, > 99\%, CAS\#03379) was purchased from Sigma-Aldrich (St. Louis, MO, USA). The HMGR assay kit (CS1090) was purchased from SigmaAldrich. The COX activity assay kit (ab 204699) was purchased from Abcam (Cambridge, UK). COX-2 and HMGR antibodies were purchased from Santa Cruz Biotechnology, Inc., USA.

\section{Cell culture}

Human colon carcinoma (HT-29) cells were obtained from American Type Culture Collection (ATCC) (Rockville, CT, USA). The cells were maintained in McCoy's 5A Medium supplemented with $100 \mathrm{U} / \mathrm{ml}$ penicillin, 100 unit/ml streptomycin sulfate and 10\% fetal calf serum at $37^{\circ} \mathrm{C}$ in a $5 \%$ carbon dioxide atmosphere incubator. OCT was diluted in ethanol at $37^{\circ} \mathrm{C}$ and shaken in an ultrasonic bath. The stock solution was stored below $-20^{\circ} \mathrm{C}$; the final amount of ethanol added to the cells was not greater than $0.1 \%(\mathrm{v} / \mathrm{v})$. This research project was approved by the institutional biosafety committee of Thammasat University (TU-IBC) (allowance no. 057-2561).

\section{Cell viability assay}

Cells were seeded onto 96-well culture plates. After an overnight culture, the cells were treated with OCT, AST or CLX for $24 \mathrm{~h}$. Cell viability was investigated by Sulforhodamine B (SRB) assay. Briefly, the cells were washed using phosphate buffered saline (PBS) and then fixed with $10 \%(\mathrm{w} / \mathrm{v})$ trichloroacetic acid. Next, the cells were stained with $0.4 \%$ SRB in $1 \%$ acetic acid for $30 \mathrm{~min}$. To remove any excess dye, the cells were then washed repeatedly with $1 \%(\mathrm{v} / \mathrm{v})$ acetic acid. The protein-bound dye was then dissolved in $10 \mathrm{mM}$ Tris base solution $\mathrm{pH} 10.5$ and incubated for $20 \mathrm{~min}$. The OD was determined at $540 \mathrm{~nm}$ using a microplate reader. Cells treated with vehicle $(0.1 \%$ ethanol) were used as a control.

\section{COX and HMGR activity assay}

After the $24 \mathrm{~h}$ treatment with OCT, AST or CLX, the cells were washed with cold PBS and then lysed in cell lysis buffer. The lysate was loaded into 96 well plates for further assay. The Pierce ${ }^{\mathrm{TM}}$ BCA Protein Assay Kit (Thermo-Scientific) was used to measure protein content; the assay was performed according to the manufacturer's protocol. Cells treated with vehicle $(0.1 \%$ ethanol) were used as a control.

The enzymatic activity of HMGR was investigated according to the manufacturer's instructions (HMGR assay kit, CS1090, Sigma-Aldrich, St. Louis, MO, USA).
Results were expressed as (mol/min)/ $\mu$ g protein. Determination of COX activity was performed according to the manufacturer's protocol (COX Activity Assay Kit Fluorimetric, Abcam ab204699, Cambridge, UK). The total amount of COX activity was expressed as ( $\mathrm{pmol} / \mathrm{min}) / \mu \mathrm{g}$ protein.

\section{Western blot analysis}

After an overnight culture in 6 well plates, the cells were treated with OCT, AST or CLX for $24 \mathrm{~h}$. Cells treated with vehicle $(0.1 \%$ ethanol) were used as a control. The cells were then washed with cold PBS and lysed in RIPA cell lysis buffer with protease inhibitor cocktail. Total protein content was estimated by Pierce ${ }^{\mathrm{TM}}$ BCA Protein Assay Kit (Thermo-Scientific) following the manufacturer's protocol. Protein (15 $\mu \mathrm{g})$ from whole-cell lysates was used for SDS-PAGE. After electrophoresis, samples were transferred to a PVDF membrane (Millipore, Boston, MA, USA) and then blocked using 5\% skim milk for $2 \mathrm{~h}$. After blocking, the membrane was rinsed 3 times with TBS-T buffer and then incubated with antibodies (anti- $\beta$-actin (sc-47778 HRP), anti-COX-2 (sc-376861 HRP) and anti-HMGR (sc271595 HRP) (Santa Cruz Biotechnology, Inc. USA) in a dilution of $1: 1000$ at $4{ }^{\circ} \mathrm{C}$ overnight. Subsequently, the membrane was washed 3 times and then developed using Western Blotting Substrate (ECL Prime Western Blotting reagent, Amersham, Buckinghamshire, UK). $\beta$-actin was used as a control to ensure equal protein loading.

\section{Statistical analysis}

Data are presented as mean \pm SD. An analysis of variance (ANOVA) was used to determine significant differences between each experimental group. The level of significance was set at $p<0.05$.

\section{RESULTS}

\section{Effect of octacosanol on inhibition of HT-29 cell growth}

To investigate the inhibitory effects of OCT on HT-29 cell growth, the cells were treated with OCT, AST or CLX in various concentrations for $24 \mathrm{~h}$. Treatment of HT-29 cells with 10 or $50 \mu \mathrm{M}$ OCT for $24 \mathrm{~h}$ did not affect cell viability, while treatment with $100 \mu \mathrm{M}$ OCT did have an affect. Exposure to AST or CLX results in cell growth inhibition in a dose-dependent manner. At the highest concentration of OCT tested $(100 \mu \mathrm{M})$, cell growth was reduced to $78 \%$ of control (approximately 20\% inhibition). Meanwhile, the highest tested concentration of AST and CLX (50 $\mu \mathrm{M}$ in both cases) reduced cell growth to $47 \%$ (about 50\% inhibition) and $38 \%$ (about $60 \%$ inhibition) of control, respectively (Fig. 1). 


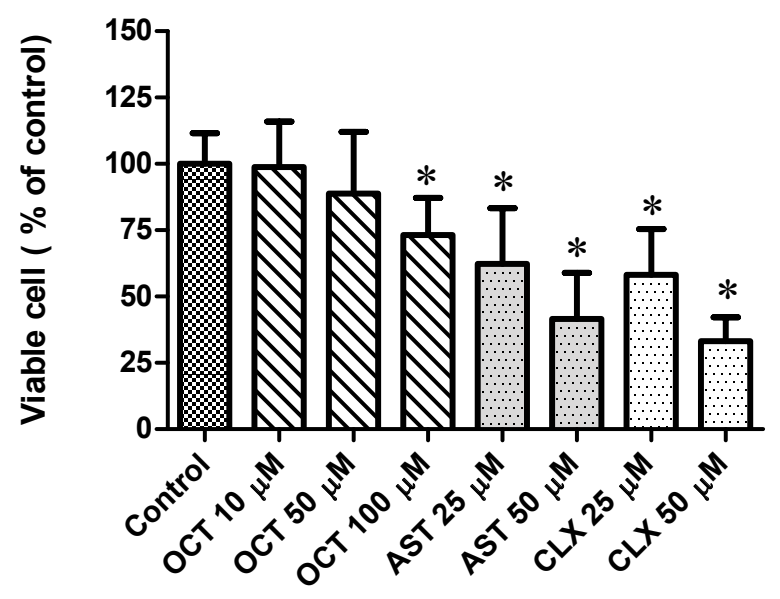

Fig. 1 Inhibitory effect of octacosanol on HT-29 cell growth. HT-29 cells were pretreated with various concentrations of octacosanol (OCT), atorvastatin (ATS) or celecoxib (CLX) for $24 \mathrm{~h}$. Cell viability was analyzed by sulforhodamine B assay. Each bar represents the mean \pm SD from 3 experiments. ${ }^{*} p<$ 0.05 compared with control.
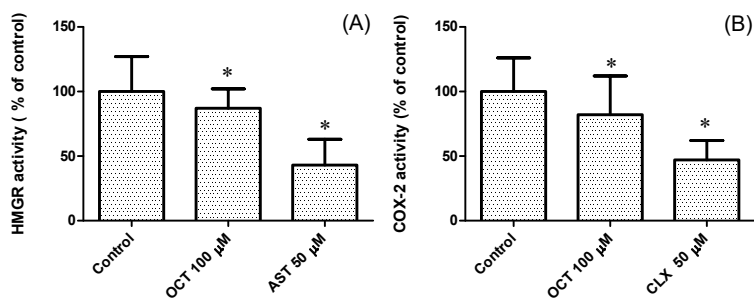

Fig. 2 Effect of OCT on HMGR and COX-2 activities. HT29 cells were cultured in $35 \mathrm{~mm}$ dishes and then incubated with $100 \mu \mathrm{M}$ octacosanol (OCT), $50 \mu \mathrm{M}$ atorvastatin (AST) or $50 \mu \mathrm{M}$ celecoxib (CLX) for $24 \mathrm{~h}$, and the activities of (COX-2) were determined using commercial kits. Each bar represents the mean $\pm \mathrm{SD}$ from 3 experiments. ${ }^{*} p<0.05$ compared with the control.

\section{Effect of octacosanol on HMGR and COX-2 activities}

OCT has been suggested to inhibit HMGR and COX2 activity $[20,21]$. Inhibition of HMGR and COX-2 activities is thought to inhibit cancer cell growth and cell cycle progression; therefore, inhibition of these enzymes may be involved in the cell growth inhibition of OCT. Cells were incubated with OCT, AST or CLX for $24 \mathrm{~h}$. Treatment with OCT or AST significantly reduced HMGR activity when compared with control (Fig. 2A). Regarding COX-2, treatment with CLX significantly reduced enzyme activity when compared with control, whereas OCT treatment demonstrated a trend towards reduced COX-2 activity ( $p=0.076$ ) (Fig. 2B). Additionally, AST and CLX demonstrated more potent abilities than OCT in terms of HMGR and COX-2 inhibition, respectively.

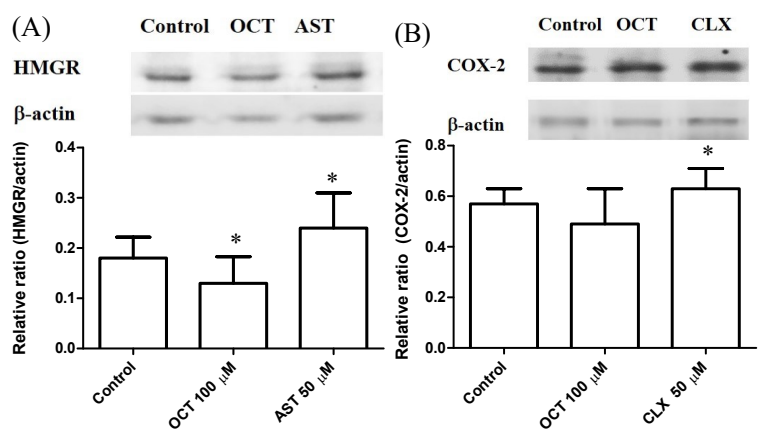

Fig. 3 Effect of octacosanol on HMGR and COX-2 protein expression. HT-29 cells were incubated with $100 \mu \mathrm{M}$ octacosanol (OCT), $50 \mu \mathrm{M}$ atorvastatin (AST) or $50 \mu \mathrm{M}$ celecoxib (CLX) for $24 \mathrm{~h}$, and then expression of HMGR (A) and COX-2 (B) proteins were determined by Western blot analysis. Each bar represents the mean \pm SD from 3 experiments. * $p<0.05$ compared with the control. Representative images from one experiment are shown.

\section{Effect of octacosanol on HMGR and COX-2 protein expression}

To examine how OCT inhibits the activity of HMGR and COX-2, the protein expressions of HMGR and COX2 were investigated. Treatment with OCT resulted in significant decreases in HMGR expression as evidenced by Western blot analysis of HMGR protein in the treated HT-29 cells (Fig. 3A). Additionally, induced HMGR protein expression was observed in HT29 cells treated with AST (Fig. 3A), while induced COX-2 protein expression was found in the CLX-treated cells (Fig. 3B). Treatment with OCT, however, did not demonstrate any significant effects on COX-2 protein expression (Fig. 3B).

\section{DISCUSSION}

Octacosanol (OCT), a long-chain fatty alcohol isolated from natural products, has multiple pharmacological functions including anti-inflammatory [19] and lipidlowering effects [20]. Atorvastatin belongs to the statin family and exerts lipid-lowering effects by inhibiting the activity of HMGR, the rate limiting enzyme in cholesterol biosynthesis. Recently, a study has demonstrated that statins exert cancer-preventing effects through regulation of cellular events including cell proliferation, differentiation, inflammation and program cell death [21]. Studies using hepatoma cells and a mice model have shown that policosanol inhibited cholesterol synthesis by down regulation of HMGR $[7,9]$. Moreover, Octacosa-10,19-dien-1-ol, an unsaturated analogue of 1-octacosanol, has shown inhibitory effects on HMGR upregulation, inducing phosphorylation of AMPK and downregulation of HMGR mRNA using a similar mechanism with policosanol [21].

Induction of prostaglandin synthesis by COX-2 
stimulates cancer cell proliferation, promotes angiogenesis, inhibits programmed cell death and increases metastatic potential [22]. COX-2 protein expression is under the regulation of NF- $\kappa \mathrm{B}$. Furthermore, MAPKs play an essential role in NF- $\kappa \mathrm{B}$ activation. CLX, a selective COX-2 inhibitor, has exhibited anti-cancer activity in several cancer models [22]; these effects may be mediated via inhibition of COX-2 and, at least partially, regulation of $\mathrm{NF}-\kappa \mathrm{B}$ activity [23]. In our study, we observed no significant differences in COX-2 activity or protein expression following OCT treatment when compared with control. Previous studies have reported anti-inflammatory effects of OCT via molecular mechanisms involving blockade of NF- $\kappa \mathrm{B}$ signaling pathway [20,21]. Additionally, policosanol, the main component of which is OCT, has been reported to inhibit COX activity in vitro [3]. In the current study, OCT treatment concentrations were limited to $100 \mu \mathrm{M}$ due to the compound's solubility; therefore, the tested concentrations may have been insufficient to provide an inhibitory effect on COX-2.

Interestingly, in the cells treated with AST or CLX, inhibition of HMGR and COX-2 activities triggered an increase in the production level of these proteins. This finding is consistent with the previous studies by Gobel et al and Ramer et al which proposed that the increase in protein levels is possibly for compensating the loss of its activity $[24,25]$.

\section{CONCLUSION}

Our data suggested that OCT possesses anti-cancer activity. This effect may be attributed to many factors including the ability of OCT to inhibit HMGR activity. However, the exact mechanisms underlying the effects of OCT on HMGR activity require further investigation.

Acknowledgements: This work was supported by a grant from Thammasat University under grant number: TP 2/5/2018 and Faculty of Medicine, Thammasat University, Thailand under grant number: TP 2-04/2018.

\section{REFERENCES}

1. Irmak S, Dunford NT (2005) Policosanol contents and compositions of wheat varieties. J Agric Food Chem 53, 5583-5586.

2. Ravelo Y, Molina V, Carbajal D, Fernandez L, Fernandez JC, Arruzazabala ML, Mas R (2011) Evaluation of anti-inflammatory and antinociceptive effects of D-002 (beeswax alcohols). J Nat Med 65, 330-335.

3. PÃlrez YMR, Oyarzábal A, Jiménez S, Molina V (2013) Effects of policosanol (sugar cane wax alcohols) and D003 (sugarcane wax acids) on cyclooxygenase (COX) enzyme activity in vitro. Int $J$ Pharm Sci Rev Res 19, 18-23.

4. Arruzazabala ML, Carbajal D, Mas R, Molina V, Valdes S, Laguna A (1994) Cholesterol-lowering effects of policosanol in rabbits. Biol Res 27, 205-208.

5. Castano G, Mas R, Fernandez L, Illnait J, Gamez R, Alvarez E (2001) Effects of policosanol 20 versus $40 \mathrm{mg} /$ - day in the treatment of patients with type II hypercholesterolemia: a 6-month double-blind study. Int J Clin Pharmacol Res 21, 43-57.

6. Cubeddu LX, Cubeddu RJ, Heimowitz T, Restrepo B, Lamas GA, Weinberg GB (2006) Comparative lipidlowering effects of policosanol and atorvastatin: a randomized, parallel, double-blind, placebo-controlled trial. Am Heart J 152, 982.e1-982.e9825.

7. Nam DE, Yun JM, Kim D, Kim OK (2019) Policosanol attenuates cholesterol synthesis via AMPK activation in hypercholesterolemic rats. J Med Food 22, 1110-1117.

8. Zhu L, Guo G, Fan Z-Q, Wang N, Zou D-Q, Shi X-Q (2021) Alleviation of high- fat-diet induced obesity and cholesterol accumulation in mice by extracts from male zooid of Antheraea pernyi. ScienceAsia 47, 162-169.

9. Singh DK, Li L, Porter TD (2006) Policosanol inhibits cholesterol synthesis in hepatoma cells by activation of AMP-kinase. J Pharmacol Exp Ther 318, 1020-1026.

10. Hashemi Goradel N, Najafi M, Salehi E, Farhood B, Mortezaee K (2019) Cyclooxygenase-2 in cancer: e̊view. J Cell Physiol 234, 5683-5699.

11. Khan Z, Khan N, Tiwari RP, Sah NK, Prasad GB, Bisen PS (2011) Biology of cox-2: an application in cancer therapeutics. Curr Drug Targets 12, 1082-1093.

12. Yarla NS, Bishayee A, Sethi G, Reddanna P, Kalle AM, Dhananjaya BL, Dowluru KS, Chintala R, et al (2016) Targeting arachidonic acid pathway by natural products for cancer prevention and therapy. Semin Cancer Biol 40-41, 48-81.

13. Kim MK, Myung SK, Tran BT, Park B (2017) Statins and risk of cancer: A meta-analysis of randomized, doubleblind, placebo-controlled trials. Indian $J$ Cancer 54, 470-477.

14. Liu BL, Vi ZB, Guan XW, Ma F, Zeng YX (2017) The relationship between statins and breast cancer prognosis varies by statin type and exposure time: A meta-analysis. Breast Cancer Res Treat 164, 1-11.

15. Paajarvi G, Roudier E, Crisby M, Hogberg J, Stenius U (2005) HMG-CoA reductase inhibitors, statins, induce phosphorylation of Mdm2 and attenuate the p53 response to DNA damage. FASEB J 19, 476-478.

16. Ridruejo E, Romero-Caimi G, Obregon MJ, Kleiman de Pisarev D, Alvarez L (2018) Potential molecular targets of statins in the prevention of hepatocarcinogenesis. Ann Hepatol 17, 490-500.

17. Herold G, Jungwirth R, Rogler G, Geerling I, Stange EF (1995) Influence of cholesterol supply on cell growth and differentiation in cultured enterocytes (CaCo-2). Digestion 56, 57-66.

18. Schointuch MN, Gilliam TP, Stine JE, Han X, Zhou C, Gehrig PA, Kim K, Bae-Jump VL (2014) Simvastatin, an HMG-CoA reductase inhibitor, exhibits anti-metastatic and anti-tumorigenic effects in endometrial cancer. $G y$ necol Oncol 134, 346-355.

19. Stine JE, Guo $H$, Sheng $X$, Han $X$, Schointuch $M N$, Gilliam TP, Gehrig PA, Zhou C, et al (2016) The HMG-CoA reductase inhibitor, simvastatin, exhibits antimetastatic and anti-tumorigenic effects in ovarian cancer. Oncotarget 7, 946-960.

20. Guo TY, Lin QL, Li XH, Nie Y, Wang L, Shi LM, Xu W, $\mathrm{Hu}$ T, et al (2017) Octacosanol attenuates inflammation in both RAW264.7 macrophages and a mouse model of colitis. J Agr Food Chem 65, 3647-3658. 
21. Oliaro-Bosso S, Calcio Gaudino E, Mantegna S, Giraudo E, Meda C, Viola F, Cravotto G (2009) Regulation of HMGCoA reductase activity by policosanol and octacosadienol, a new synthetic analogue of octacosanol. Lipids 44, 907-916.

22. Subbaramaiah K, Dannenberg AJ (2003) Cyclooxygenase 2: a molecular target for cancer prevention and treatment. Trends Pharmacol Sci 24, 96-102.

23. Zuo C, Hong Y, Qiu X, Yang D, Liu N, Sheng X, Zhou $\mathrm{K}$, Tang B, et al (2018) Celecoxib suppresses proliferation and metastasis of pancreatic cancer cells by down- regulating STAT3/NF- $\kappa \mathrm{B}$ and L1CAM activities. Pancreatology 18, 328-333.

24. Gobel A, Breining D, Rauner M, Hofbauer LC, Rachner TD (2019) Induction of 3-hydroxy-3-methylglutarylCoA reductase mediates statin resistance in breast cancer cells. Cell Death Dis 10, ID 91.

25. Ramer R, Walther U, Borchert P, Laufer S, Linnebacher M, Hinz B (2013) Induction but not inhibition of COX-2 confers human lung cancer cell apoptosis by celecoxib. J Lipid Res 54, 3116-3129. 